\title{
Foreign Exchange Volatility, Media Coverage, and the Mixture of Distributions Hypothesis: Evidence from the Chinese Renminbi Currency
}

\author{
$\underline{\text { Y.Shi }}^{\text {a }}$, K.Y. Ho ${ }^{\text {a }}$, W.M. Liu ${ }^{\text {a }}$ \\ ${ }^{a}$ School of Finance, Actuarial Studies and Applied Statistics, College of Business and Economics, The \\ Australian National University, Canberra, Australia \\ Email:yanlin.shi@anu.edu.au
}

\begin{abstract}
The stability of Chinese renminbi (CNY) against the US dollar (USD) has been the recent focus of economic and political discussion in the media, especially in light of the growing political pressure exerted by the US government to let the CNY/USD appreciate. This paper contributes to the discussion of the CNY/USD stability by examining its volatility dynamics since the floating regime is established. In particular, we analyze the fluctuations of the CNY/USD from the perspective of the mixture of distributions hypothesis (MDH), which argues that the variability of financial assets at a given interval is proportional to the rate of public information arrivals. By using the well-known news database FACTIVA, which offers a comprehensive collection of the world's top media outlets and publications (such as The Wall Street Journal and The New York Times) in Chinese and English languages, we document the statistical significance of the impact of information arrivals on the conditional volatility of the CNY/USD.
\end{abstract}

More specifically, information arrivals are measured by the number of news items that appear in the various major media sources for each day from July 212005 (which marks the first day of the floating regime). The media sources comprise not only the top ten English-language US newspapers (by circulation numbers) but also the twelve major Chinese-language media publications in the Asia-Pacific region (including five from mainland China, two from Hong Kong SAR, and three from Taiwan). These Chinese publications are selected on the basis of wide regional and global readership. The relevant news items from all the media sources can be broadly classified into two categories: macroeconomic news containing relevant information on the CNY exchange rate and political news on the Sino-US relations.

We adopt two main approaches to analyze the link between public news and the CNY/USD volatility. First, by applying the Generalized Autoregressive Conditional Heteroskedasticity (GARCH) framework that incorporates asymmetric effects and conditional leptokurtic distributions to the daily spot CNY/USD data for the period from July 212005 - December 312010 , we observe that there is a significantly positive impact of all the daily public news items on the conditional volatility of CNY/USD. This result is robust across alternative model specifications and distributional assumptions. Amongst all the different models, the Exponential GARCH-in-Mean (EGARCH-M) with conditional Student-t distribution works best for the daily data. In particular, compared with the EGARCH-M model with no news effects, the volatility persistence in the EGARCH-M model with news is reduced. As a further robustness check, our analysis is also extended to the daily non-deliverable forward (NDF) rates for various maturities. Consistent with the results for the spot rates, public news arrivals have a positive impact on the conditional volatility of the NDFs.

Our second approach is to use the framework of Bauwens, Rime, and Sucarrat (2006) by computing realized volatility measures for weekly CNY/USD rates. Consistent with the results obtained for the daily data, public news has a positive impact on CNY/USD volatility. Range-based volatility measures are also used and they confirm the positive link between exchange rate volatility and public news. In general, our results suggest that the intensity of media coverage is a significant determinant of the volatility dynamics of the CNY/USD exchange rate.

Keywords: $\quad$ Exchange rate volatility, Media Coverage, Mixture of distribution hypothesis, Nondeliverable forward 


\section{INTRODUCTION}

Since the mid-1990s, the Chinese renminbi (CNY) has undergone a series of exchange rate reforms before evolving into its present form. In 1994, the dual-track regime involving a swap rate system was replaced by a unified fixed rate of 8.26 CNY per US dollar (USD), which implied a one-off depreciation of the official exchange rate. At about the same period, the CNY non-deliverable forward (NDF) market began to expand, with rapid increases in trading volume since 2002 (Zhang, 2004; Peng et al, 2007; Zhang and Chan, 2010). Subsequently, on July 212005 , the rigid fixed-rate system was superseded by the current managed-floating regime, which pegged the CNY against a basket of currencies (Liu and Pauwels, 2008). Concurrently, the average daily trading volume in the CNY NDF market was around US\$1 billion and this increased to around US\$2.5-3 billion per day in 2007 (Peng et al, 2007).

The developments in the CNY spot and NDF markets have created points of significant international discussion and controversy. Amongst other things, it is often alleged that the CNY is undervalued and this delivered an unfair advantage to Chinese export enterprises. In addition, the gradual internationalization of the CNY before complete capital account convertibility has generated heated debate on the future regional and global status of the CNY (Lo, 2010; Zhang and Chan, 2010). Internationalization can create an expanding offshore market and increase CNY trading. For instance, the use of CNY is already rising for border trades in Myanmar, Mongolia, Laos, and Russia. It is anticipated that the combination of a managedfloat regime and CNY internationalization will most likely lead to greater and sustained variability in the CNY/USD exchange rate.

Apart from increased trading in the spot and offshore CNY markets, public information flows in the markets can also influence the variability of the CNY/USD rate. It is a well-established paradigm in finance that asset prices and volatility are affected by new information arrivals (Berry and Howe, 1994; Kalev et al, 2004; Fang, and Peress, 2009). In particular, it is noted that foreign exchange markets are highly sensitive to macroeconomic and political news announcements (Melvin and Yin, 2000; Chang and Taylor, 2003; Bauwens et al, 2006; Liu and Pauwels, 2008). As such, CNY market participants around the world most likely have to pay attention to the impact of news flows on fluctuations in the exchange rate. The role of public information arrivals on currency volatility is expected to become more prominent, with increased use of the CNY.

In this paper, we propose the application of the mixture of distributions hypothesis (MDH) to the study of the relationship between public information arrivals and the volatility of the CNY/USD rate. The MDH posits that asset volatility is proportional to the rate of information arrival in the market (Clark, 1973; Tauchen and Pitts, 1983; Lamoureux and Lastrapes, 1990). As a proxy for information arrivals, the early MDH literature makes use of asset trading volume. This approach is problematic, in part because trading volume cannot be assumed to be exogenous, given that both volatility and trading volume are simultaneously affected by a common latent information arrival process. Furthermore, trading volume could be liquidity driven. In the context of foreign exchange, quote frequency is often adopted as a proxy (Melvin and Yin, 2000; Bauwens et al, 2006), but the disadvantage is that it may not purely indicate public information flows.

To overcome these shortcomings, we broaden our scope of public information arrivals by capturing a wide range of news items related to the CNY/USD rate from the well-known Dow Jones FACTIVA database. Relevant English and Chinese articles are selected from FACTIVA based on circulation numbers of the media publications. These articles are either macroeconomic news containing relevant information on the CNY exchange rate or political news on the Sino-US relations. In addition, we consider the impact of these public information flows on both the spot and NDF rates. To confirm the robustness of our results, both the daily and weekly rates are analyzed. Specifically, for the daily data, we employ the popular Generalized Autoregressive Conditional Heteroskedasticity (GARCH) framework with asymmetric volatility effects and leptokurtic distributions (Bollerslev et al, 1992; Park, 2010). As for the weekly data, we apply several realized and range-based volatility measures in a multivariate regression model to examine the relationship between CNY/USD volatility and public information flows.

Consistent with the MDH, our findings for both daily and weekly data indicate a significantly positive relationship between public information arrival rates and exchange rate volatility. Furthermore, the volatility is negatively related to the daily CNY/USD return, which implies that heightened exchange rate uncertainty increases the pressure of CNY/USD appreciation in future. These findings suggest that, to the extent that the central bank is concerned with the overall stability of the CNY/USD rate, the dynamics of public information arrivals cannot be ignored. 


\section{DATA AND SAMPLE}

\subsection{Return and volatility of the spot and NDF rates series}

Our sample includes daily spot and 12 months NDF rates of CNY/USD ranging from July 21, 2005 to December 31, 2010, which are supplied by Thomson Reuters. The variables are defined as follows.

Define $\left\{S_{0}, S_{1}, \ldots, S_{T-1}, S_{T}\right\}$ as the sequence of daily exchange rates of CNY/USD at times $\{0,1, \ldots, T-1$, $T\}$. The return of the exchange rate on date $t$ is given by:

$$
r_{t}^{d}=100 \times \log \left(S_{t} / S_{t-1}\right) .
$$

Define $r_{t(n)}^{d}$ as the daily return of the exchange rate on day $t$ of week $n$, the log transformation of the weekly realized volatility is given by (Andersen et al. 2003):

$$
r v_{n}=\log \left(R V_{n}\right)=\log \left(\sum_{t=1}^{5}\left(r_{t(n)}^{d}\right)^{2}\right) .
$$

We have two types of weekly range volatility. The first type is based on the log transformation of Parkinson's (1980) intra-period high-low measure:

$$
r n v a_{n}=\log \left(\left\{\log \left[\max \left\{S_{t(n)}\right\} / \min \left\{S_{t(n)}\right\}\right]\right\}^{2} / 4 \log 2\right),
$$

where $S_{t(n)}$ the daily spot rate on day $t$ of week $n$. The second type is based on the log transformation of Garman and Klass's (1980) intra-period high-low measure:

$$
r n v b_{n}=\log \left(0.5\left\{\log \left[\max \left\{S_{t(n)}\right\} / \min \left\{S_{t(n)}\right\}\right]\right\}^{2}-0.39\left\{\log \left[S_{5(n)} / S_{1(n)}\right]\right\}^{2}\right) .
$$

\subsection{Rate of information arrival series}

We proxy the daily information arrivals using the number of daily news articles extracted from FACTIVA in the period between July 21, 2005 and December 31, 2010. Denote $\left\{N_{0}, N_{I}, \ldots, N_{T-I}, N_{T}\right\}$ as a sequence of numbers of daily news articles at date $\{0,1, \ldots, T-1, T\}$. The daily and the weekly news rate are given by:

$$
\begin{aligned}
& W_{t}^{d}=N_{t} / N_{t-1}, \\
& W_{n}^{w}=\sum_{t=1}^{7} N_{t(n)} / \sum_{t=1}^{7} N_{t(n-1)} .
\end{aligned}
$$

and the corresponding $\log$ transformation are given by: $w_{t}^{d}=\log \left(W_{t}^{d}\right)$ and $w_{n}^{w}=\log \left(W_{n}^{w}\right) \cdot N_{t(n)}$ is the number of news articles on day $t$ of week $n$.

\section{METHODOLOGY AND MODEL SPECIFICATION}

\subsection{Mixture of Distribution Hypothesis (MDH)}

Let us define the following variables. Define $\Delta S_{i}$ as the intraday change of the exchange rate. $\Delta S_{i}$ is independently and identically (normally) distributed with the constant variance $\sigma^{2}$, i.e. $\Delta S_{i} \sim N\left(0, \sigma^{2}\right)$. Define $I(t)$ as the number of increments on day $t$. Then the daily change of exchange rate on day $t, \Delta S_{t}$ is given by:

$$
\Delta S_{t}=\sum_{i=1}^{I(t)} \Delta S_{i}, i=1, \ldots, I(t), \Delta S_{0}=\Delta S_{I(t-1)} .
$$

Using expression (1), $\Delta S_{t}$ in expression (7) can be rewritten as:

$$
r_{t}^{d}=\sum_{i=1}^{I(t)} r_{i}^{d}, i=1, \ldots, I(t), r_{0}^{d}=r_{I(t-1)}^{d} .
$$

where $r_{i}^{d^{d i d}} \sim N\left(0, \sigma_{c}^{2}\right)$ and $\sigma_{c}^{2}$ is a constant. The conditional volatility of daily return is thus given by: 


$$
h_{t}=\operatorname{Var}\left(r_{t}^{d} \mid t\right)=\operatorname{Var}\left(\sum_{i=1}^{I(t)} r_{i}^{d} \mid t\right)=\sigma_{c}^{2} I(t) .
$$

As can be seen, the conditional volatility of daily return will fully depend on the value of $I(t)$. Clark (1973) argues that $I(t)$ can be proxied by the daily trading volume. Tauchen and Pitts (1983) further argue that the average daily trading volume is proportional to daily rate of information arrival $n_{t} / n_{t-1}$, that is,

$$
E\left(V_{t}\right) \propto n_{t} / n_{t-1} .
$$

where $V_{t}$ is the daily trading volume on day $t$. This implies that the number of increments is also proportional to the news rate in the same period, which means that

$$
I(t) \propto n_{t} / n_{t-1} .
$$

Based on the above argument purported by Clark (1973) and Tauchen and Pitts (1983), we assert that the volatility of the return of exchange rate at a given interval could be proportional to the rate of information arrival in the same period.

$$
h_{t} \propto n_{t} / n_{t-1} .
$$

For the reasons discussed in section 1, we will use the rate of news articles as a proxy of numbers of increment in MDH in our study. Furthermore, by taking log of the expression (12), we have

$$
\log \left(h_{t}\right) \propto \log \left(n_{t} / n_{t-1}\right),
$$

which is considered to be a more appropriate (see, for example, Andersen et al. (2001) and Bauwens et al (2006)) approach because the variable is closer to the normal distribution. Besides, since the volatilities cannot be negative, Nelson (1991) proposes that volatilities should be analyzed in logarithm, where the non-negativity will be ensured.

\subsection{Modelling Daily Data using GARCH family models}

For daily data, we model conditional volatility using GARCH family models, which is widely used in modelling return volatility in financial data (Bollerslev, Chou and Kroner, 1992; Park 2010; among others). In particular, we use the Exponential-GARCH-in-mean (EGARCH-M) model. The reason is that it has the largest log-likelihood value in all the alternative models, while the number of variables is the same as the others. The mean equation and conditional variance equation are specified as follows:

\section{Mean Equation}

In the mean equation, an $\mathrm{AR}(5)$ model is found to capture the serial correlation adequately. To examine how the return of the exchange rate is affected by uncertainty, we add the conditional volatility term in the mean equation. Thus, the mean equation of the daily CNY/USD return series is:

$$
r_{t}^{d}=b_{0}+\sum_{i=1}^{5} b_{i} r_{t-i}^{d}+\lambda h_{t}+\varepsilon_{t},
$$

where $\varepsilon_{t}$ is the residual at time $t . h_{t}$ is the variance of $\varepsilon_{t}$ conditioned on time $t . \lambda$ is the estimated parameter of $h_{t}$ and in Table 1 it is denoted by GARCH-M.

\section{Conditional Variance Equation}

To test the MDH, we include the log news rate $w_{t}^{d}$ in the conditional variance equation of our EGARCH-M model:

$$
\log \left(h_{t}\right)=c+\alpha \frac{\left|\varepsilon_{t-1}\right|}{\sqrt{h_{t-1}}}+\beta \log \left(h_{t-1}\right)+\gamma \frac{\varepsilon_{t-1}}{\sqrt{h_{t-1}}}+\phi w_{t}^{d}
$$

In expression (15), the parameter $\beta$ measures the volatility persistence, which is how fast the current shock to the volatility will die away. A large $\beta$ indicates the current shock will affect the volatility in the long run. The parameter $\gamma$ measures the asymmetric effect, which assesses whether the positive and negative shocks will affect the volatility differently. If so, the estimate of $\gamma$ will be significantly different from 0 . 


\subsection{Weekly Data}

For weekly data, we test the MDH using multivariate regressions on realized volatility and two types of range volatility. Similar to Bauwens, Rime and Sucarrat (2006), we employ AR(5) model to the realized volatility and range volatility measures. The three model specifications are as follows.

$$
\begin{aligned}
& r v_{t}=b_{0}+\sum_{i=1}^{5} b_{i} r v_{t-i}+\phi w_{t}^{w}+\varepsilon_{t} \\
& r n v a_{t}=b_{0}+\sum_{i=1}^{5} b_{i} r n v a_{t-i}+\phi w_{t}^{w}+\varepsilon_{t} \\
& r n v b_{t}=b_{0}+\sum_{i=1}^{5} b_{i} r n v b_{t-i}+\phi w_{t}^{w}+\varepsilon_{t}
\end{aligned}
$$

\section{EMPIRICAL RESULTS AND IMPLICATION}

\subsection{Daily Data}

Before estimating our full model, two regressions of EGARCH-M without news effect are fitted, where Gaussian and student $t$ distribution assumptions of the residuals are tested respectively. Since the JarqueBera statistic of the Gaussian distribution assumption model is quite large, and the likelihood-ratio test (LRT) of the two models has a $p$-value very close to 0 , the $t$-distribution assumption is preferred. Regression outputs are available upon request. As a result, all the following estimations are regressed under the $t$-distribution assumption.

\section{Empirical Results and Implications}

Two different specifications of EGARCH-M, with and without news variable are estimated for comparison and the results are in Table 1. Firstly, it can be seen that both the conditional variance terms in the mean equation are negatively significant with the absolute value a bit larger than 1 . It is indicated heightened uncertainty will significantly reduce the daily return.

In our conditional variance equations, the estimated impact of the news arrival rate is positive and are significant at all conventional levels including $5 \%$ and $1 \%$ with the estimate around 0.84 . That means that $1 \%$ increase in the daily news arrival rate leads to, an average, $0.84 \%$ increase in the conditional volatility of daily return. Another important issue is the reduction in volatility persistence. As shown in Table 1 , the estimated value of $\beta$ has decreased from 0.9915 to 0.9895 . The $\log$-likelihood value increases significantly with the $p$-value of LRT close to 0 , implying that the inclusion of the

\begin{tabular}{|c|c|c|c|c|}
\hline & \multicolumn{2}{|c|}{ Without News Var. } & \multicolumn{2}{|c|}{ With News Var. } \\
\hline & Est. & Pval. & Est. & Pval. \\
\hline GARCH-M & -1.2239 & 0.0000 & -1.1557 & 0.0000 \\
\hline$\alpha$ & 0.2661 & 0.0000 & 0.3182 & 0.0000 \\
\hline$\gamma$ & -0.0344 & 0.1186 & -0.0340 & 0.1707 \\
\hline$\beta$ & 0.9915 & 0.0000 & 0.9895 & 0.0000 \\
\hline$\phi$ & & & 0.8366 & 0.0000 \\
\hline $\log L$ & 1830.856 & & 1849.276 & \\
\hline$L R T$ & 15.278 & 0.0001 & 36.840 & 0.0000 \\
\hline$Q(10)$ & 8.1749 & 0.6120 & 9.3143 & 0.5030 \\
\hline$A R C H_{1-10}$ & 2.5994 & 0.9893 & 15.8389 & 0.1043 \\
\hline
\end{tabular}
news variable into the conditional variance

Table 1. Regressions of the EGARCH-M Models

Estimates are obtained based on the Maximum Likelihood using Berndt-Hall-Hall-Hausman algorithm. Pval. stands for p-value and corresponds to a two-sided test with zero as null, $\log L$. stands for log-likelihood, $L R T$ stands for the likelihood ratio test for comparing the fit of two models, $Q(10)$ is the Ljung and Box test for serial correlation in the standardized residuals up to lag 10 , and $A R C H_{1-10}$ is the Chi-Square-form of the Lagrange-mulitplier test for serial correlation in the squared standardized residuals up to lag 10. equation significantly improves the overall goodness-of-fit of the model. Finally, we have little evidence of asymmetry effect in the conditional variance as the estimates of $\gamma$ in both specifications are not significant at the $10 \%$ level.

Overall, our EGARCH-M result has strong support of the $\mathrm{MDH}$ as the information arrival rate significantly and positively influences the conditional volatility and volatility persistence.

\subsection{Weekly Data}

The empirical results of two AR(5) models on weekly volatility measures (with and without the news arrival rate) are presented in Table 2. 
From Table 2, it is clear that the estimated results of realized volatility and two range volatilities and quite similar. In particular, for realized volatility, the estimated impacts of the information arrival rates carry the hypothesized positive sign and are significant at $5 \%$ level, with the estimate around 0.75 . The overall goodness-of-fit is also significantly improved by adding the news rate variable. Thus, both of the results are consistent with the daily case.

Turning to the case of range volatilities, it is noted that the log news rates are positively significant at $10 \%$ level, with the estimates around 0.70 and 0.76 . In general, the variables of log information arrivals are all individually significant at $10 \%$ level, and the overall goodness-offit are all significantly improved at 5\% level in the weekly case. Thus, our estimated results provide further corroborating evidence for the $\mathrm{MDH}$ as mentioned in section 3.1.

\subsection{Robustness Check}

Liu and Pauwels (2008) argue that the 12 months NDF rates of CNY/USD can be used to proxy the spot rates of $\mathrm{CNY} / \mathrm{USD}$. We repeat the above empirical exercises using the daily and the weekly 12 month NDF rates of CNY/USD. Results will be provided upon request. Overall, our conclusion is unchanged. The only difference is that the conditional variance term of the daily NDF rates in the mean equation is not significant at $10 \%$ level, indicating the uncertainty cannot significantly affect the daily return. The individual significance of news variable, the reduction in volatility persistence and the improvement of the overall Table 2. Regressions of the Weekly Volatilities

\begin{tabular}{|c|c|c|c|c|}
\hline & \multicolumn{2}{|c|}{ Realized Vol. without News } & \multicolumn{2}{|c|}{ Realized Vol. with News } \\
\hline & Est. & Pval. & Est. & Pval. \\
\hline$\phi$ & & & 0.7451 & 0.0286 \\
\hline $\log L$ & -441.2058 & & -436.7427 & \\
\hline$L R T$ & & & 8.9262 & 0.0028 \\
\hline$Q(10)$ & 5.6066 & 0.8470 & 7.4508 & 0.6820 \\
\hline \multirow[t]{3}{*}{$A R C H_{1-10}$} & 15.1990 & 0.1250 & 15.8011 & 0.1055 \\
\hline & \multicolumn{2}{|c|}{ Range I Vol. without News } & \multicolumn{2}{|c|}{ Range I Vol. with News } \\
\hline & Est. & Pval. & Est. & Pval. \\
\hline$\phi$ & & & 0.6973 & 0.0705 \\
\hline $\log L$ & -492.3464 & & -489.6800 & \\
\hline$L R T$ & & & 5.3328 & 0.0209 \\
\hline$Q(10)$ & 12.977 & 0.225 & 13.188 & 0.213 \\
\hline \multirow[t]{3}{*}{$A R C H_{1-10}$} & 10.25182 & 0.4187 & 11.29213 & 0.3352 \\
\hline & \multicolumn{2}{|c|}{ Range II Vol. without News } & \multicolumn{2}{|c|}{ Range II Vol. with News } \\
\hline & Est. & Pval. & Est. & Pval. \\
\hline$\phi$ & & & 0.7663 & 0.0539 \\
\hline $\log L$ & -495.6014 & & -492.4890 & \\
\hline$L R T$ & & & 6.2248 & 0.0125 \\
\hline$Q(10)$ & 9.5866 & 0.4770 & 10.8520 & 0.3690 \\
\hline$A R C H_{1-10}$ & 5.8428 & 0.8283 & 5.5334 & 0.8528 \\
\hline
\end{tabular}

Estimates are obtained based on Least Squares with heteroscedasticity consistent standard errors of the White (1980) type. For others notations see Table 1 for details. goodness-of-fit are quite similar to the spot cases. Hence, our robust estimations are also consistent with the idea of MDH.

\section{CONCLUSION AND FURTHER STUDY}

Our paper contributes to the discussion of the CNY/USD stability by examining its volatility dynamics since the floating regime is established from July 21, 2005. Using the argument of MDH originated by Clark (1973) and others, which shows that the variability of security prices at a given interval is proportional to the rate of public information arrival, we examine the linkage between CNY/USD stability and media coverage. By using the well-known news database FACTIVA, our results indicate that the intensity of media coverage is a significant determinant of the volatility dynamics of the CNY/USD exchange rate. Furthermore, the reduction in volatility persistence, together with the significant positive impact of the information arrival rate, can be considered as evidence in support of the MDH. We extend our analysis to 12-month CNY/USD forward rate and find qualitatively similar results.

The reduction in volatility persistence is limited compared with similar works on other foreign exchange rates (Bauwens et al 2006). One possible explanation is that the number of daily news items extracted from FACTIVA can only be regarded as a "quantitative measure" of the public information arrivals in the markets. It does not indicate other important characteristics such as market sentiment, which can also induce significant and sustained fluctuations in the exchange rate. As such, apart from examining the intensity of media coverage, one area of future research is to apply the technique of content analysis to the news items to develop sentiment scores and relate these scores directly to the volatility dynamics of the $\mathrm{CNY} / \mathrm{USD}$ rate. 
Shi et al., Foreign Exchange Volatility, Media Coverage, and the Mixture of Distributions Hypothesis...

\section{REFERENCES}

Andersen, T. G., Bollerslev, T., Diebold, F. X. and Labys, P. (2001), The distribution of realized exchange rate volatility, Journal of the American Statistical Association, 96, 42-55.

Andersen, T. G., Bollerslev, T., Diebold, F. X. and Labys, P. (2003). Modeling and Forecasting Realized Volatility, Econometrica, 71, 529-626.

Bauwens, L., Rime, D. and Sucarrat, G. (2006). Exchange Rate Volatility and the Mixture of Distribution Hypothesis. Empirical Economics, 30, 889-911.

Berry, T., and Howe, K. (1994). Public Information Arrival. Journal of Finance, 49, 1331-1346.

Parkinson, M. (1980). The extreme value method for estimating the variance of the rate of return. Journal of Business 53, 61-65.

Bollerslev, T., Chou, R. and Kroner, K. (1992). ARCH modelling in finance: A review of the theory and empirical evidence, Journal of Econometrics 52, 5-59.

Clark, P. (1973). A subordinated stochastic process model with finite variance for speculative Prices, Econometrica, 41, 135-155.

Fang, L. and J. Peress (2009). Media coverage and the cross-section of stock returns. Journal of Finance, 64, 2023-2052.

Garman, M., and Klass, M. (1980). On the estimation of security price volatilities from historical data, Journal of Business, 53, 67-78.

Kalev, P., Liu, W., Pham, P., and Jarnecic, E. (2004). Public Information Arrival and Volatility of Intraday Stock Returns. Journal of Banking and Finance 28, 1441-1467.

Lamoureux, C., and Lastrapes, W. (1990). Heteroskedasticity in stock return data: Volume versus GARCH effects. Journal of Finance, 45, 221-229.

Liu, L., and Pauwels, L. (2008). Do External Political Pressures Affect the Renminbi Exchange Rate?, Hong Kong Monetary Authority, Working Paper, 0805.

Lo, C. (2010). The Myth of the Internationalization of the Chinese Yuan. The International Economy Fall 2010, 30-33.

Melvin, M. and Yin, X. (2000). Public Information Arrival, Exchange Rate Volatility, and Quote Frequency. The Economic Journal, 465, 644-661.

Nelson, D. B. (1991). Conditional heteroscedasticity in asset returns: a new approach. Econometrica, 51, 485-505.

Park, B. (2010). Surprising information, the MDH, and the relationship between volatility and trading volume. Journal of Financial Markets, 13, 344-366.

Peng, W., Shu, C., and Yip, R. (2007). Renminbi Derivatives: Recent Development and Issues. China and the World Economy, 15, 1-17.

Tauchen, G. and Pitts, M. (1983). The price variability-volume relationship on speculative markets, Econometrica, 51,485-505.

Zhang, P. (2004). Chinese Yuan (Renminbi) Derivative Products. Singapore: World Scientific.

Zhang, P., and Chan, T. (2010). The Chinese Yuan: Internationalization and Financial Products in China. New York: John Wiley and Sons. 